\title{
Vortex rope instabilities in a model of conical draft tube
}

\author{
Sergey Skripkin ${ }^{1, *}$, Mikhail Tsoy ${ }^{1}$, Pavel Kuibin ${ }^{1}$ and Sergey Shtork ${ }^{1}$ \\ ${ }^{1}$ Kutateladze Institute of Thermophysics, Lavrentiev avenue 1, 630090, Novosibirsk, Russia
}

\begin{abstract}
We report on experimental studies of the formation of vortex ropes in a laboratory simplified model of hydroturbine draft tube. Work is focused on the observation of various flow patterns at the different rotational speed of turbine runner at fixed flow rate. The measurements involve high-speed visualization and pressure pulsations recordings. Draft tube wall pressure pulsations are registered by pressure transducer for different flow regimes. Vortex rope precession frequency were calculated using FFT transform. The experiments showed interesting features of precessing vortex rope like twin spiral and formation of vortex ring.
\end{abstract}

\section{Introduction}

Vortex ropes are often formed in draft tubes of hydraulic turbines operating under partial load or overload conditions. The precessing vortex core (PVC) is associated with strong pressure pulsation commonly called draft-tube surge. Interaction of the PVC with draft tube elbow has negative impact on whole hydrodynamic system. When precession frequency approaches to acoustic eigenfrequency of hydraulic unit, the resonance phenomenon is appeared. It may lead to serious negative consequences as mechanical damage, efficiency and safety decreasing. Thus, the study of the phenomenon of vortex rope formation in hydraulic turbines is an important task.

Draft tube surge has been investigated for a long time both numerically and experimentally, usually on scaled hydro turbine models. Numerous publications related to investigations of flow regimes in draft tube can be found in literature [1-3]. It is well known that the pattern, precession frequency and intensity of the vortex rope dependent on the operating mode of hydraulic turbine. However, a large number of swirl devices used as a model of the runner constantly expand and complement the information on a variety of PVC patterns. The main vortex can be replaced by twin spiral vortex, whereby the frequency of the pressure pulsations in hydraulic unit becomes unpredictable in certain part load conditions $[4,5]$. In turbine regime, close to the optimum, the pattern of vortex rope becomes unstable and constantly changes [6].

In this study, experimental modelling of swirling flow under the hydraulic turbine runner have been conducted. Experiments include high-speed visualization and pressure measurements at a fixed flow rate of fluid and varying the speed of the runner.

*Corresponding author: skripkin.s.g@gmail.com 


\section{Experimental setup and measurement equipment}

The swirl generator modelling of turbine runner consists of two swirlers: the first with fixed vanes and the second is a forcedly rotating runner. We used magnetic coupling between the motor on the dry side of turbine model and the runner in the water on the other side which transfers torque from the electric motor to runner. Thus, we manage the runner by controlling the motor rotational speed. This swirl device was designed similarly the swirl generator designed at Politehnical University of Timisoara [7]. The main idea of using the simplified draft tube model is not a complete reproduction of whole hydro turbine unit but the reconstruction of velocity profile close to distribution under nature turbine runner. Also conical draft tube model excludes the effect of interaction between PVC and draft tube elbow. Because the flow regime in this system dependent on the flow rate $\mathrm{Q}$ and the runner rotational speed $\mathrm{N}$, all experiments were conducted at the fixed flow rate $\mathrm{Q}=80 \mathrm{~m}^{3} / \mathrm{h}$ (it is correspond $\operatorname{Re} \approx 10^{5}$ ) and rotational speed from 0 to $1000 \mathrm{rpm}$. Changing one parameter allows to completely cover the whole map of the flow regimes at fixed Reynolds number.

Pressure fluctuations measurements and vortex rope visualizations are carried out on a simplified draft tube model. We used high-speed cam PCO 1200 hs and Canon 7D for detail investigations the main patterns of the PVC in different regimes. Quantitative data on the pressure pulsation and the precession frequency of vortex rope were obtained after signal processing from a pressure sensor Keller PA-4LC mounted in the wall of the draft tube.

\section{Visualisation and pressure measurements}

The swirl flow in a conical draft tube model is divided into several main regimes depending on the runner rotational speed at fixed discharge. Regime map is shown in fig. 1, where each vortex rope is illustrated at different $\mathrm{N}$. As it is shown in work [3], the shape of vortex rope and its behaviour depend on the stagnation point which moves along the centre axis in a conical part.

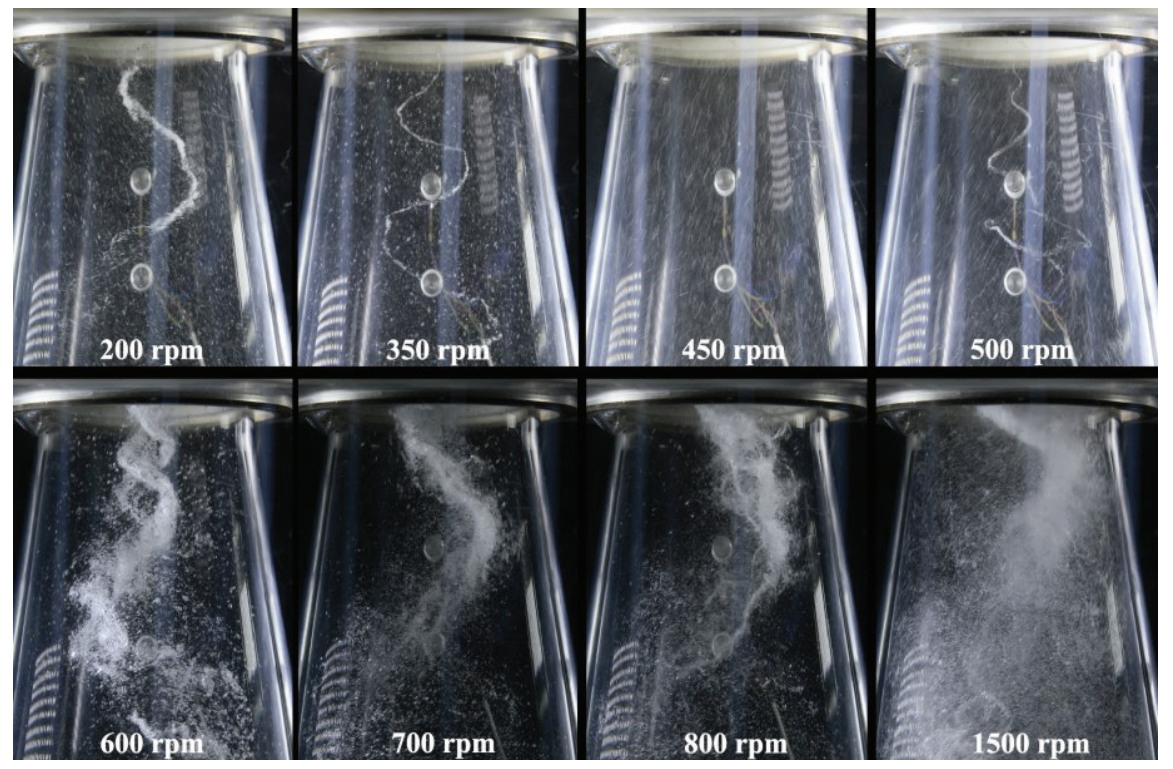

Fig. 1. Vortex rope visualisation at constant flowrate $Q=80 \mathrm{~m}^{3} / \mathrm{h}$ by varying runner rotational speed 
Thus, at the rotational speed from 0 to $450 \mathrm{rpm}$ flow is swirled counter clockwise. In region about $450 \mathrm{rpm}$ the swirl of flow is close to zero. In this regime, there is straight axially symmetric vortex rope, at the end of which the spiral vortex breakdown is observed (fig. 2). At rotational speed, more than 450 the flow is swirled clockwise and with increasing runner rotational speed $(\mathrm{N}>500 \mathrm{rpm})$ swirl of flow increases and thin spiral vortex visualized cavitation is formed. This vortex pattern is interesting in that the shape of the PVC is not stable and formation of vortex rings due to process of self-reconnection is observed (fig 2).
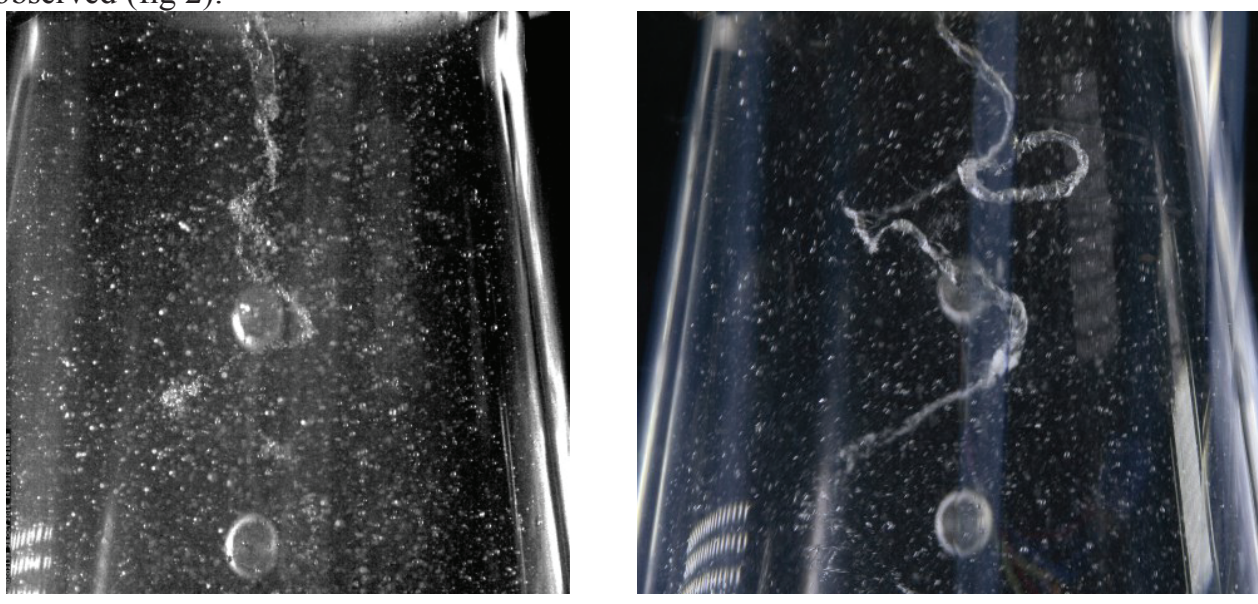

Fig. 2. The view of axially symmetric vortex rope (left) and formation of isolated vortex ring (right)

Vortex ring moves close to the wall of the draft tube, and presumably can cause strong pressure pulsations. With a further increase of speed of the runner vortex rope is intensified, cavitation cavity increases. At rotation frequency about $600 \mathrm{rpm}$ there is an unstable formation of the twin vortex, with a predominance of single mode. With further increasing rotational frequency $(\mathrm{N}>700 \mathrm{rpm})$ vortex rope replaced by a large number of small vortices rotating as one.

Also, experiments on study the draft tube wall pressure pulsation were conducted. The figure 3 shows the graphs obtained by fast Fourier transform.

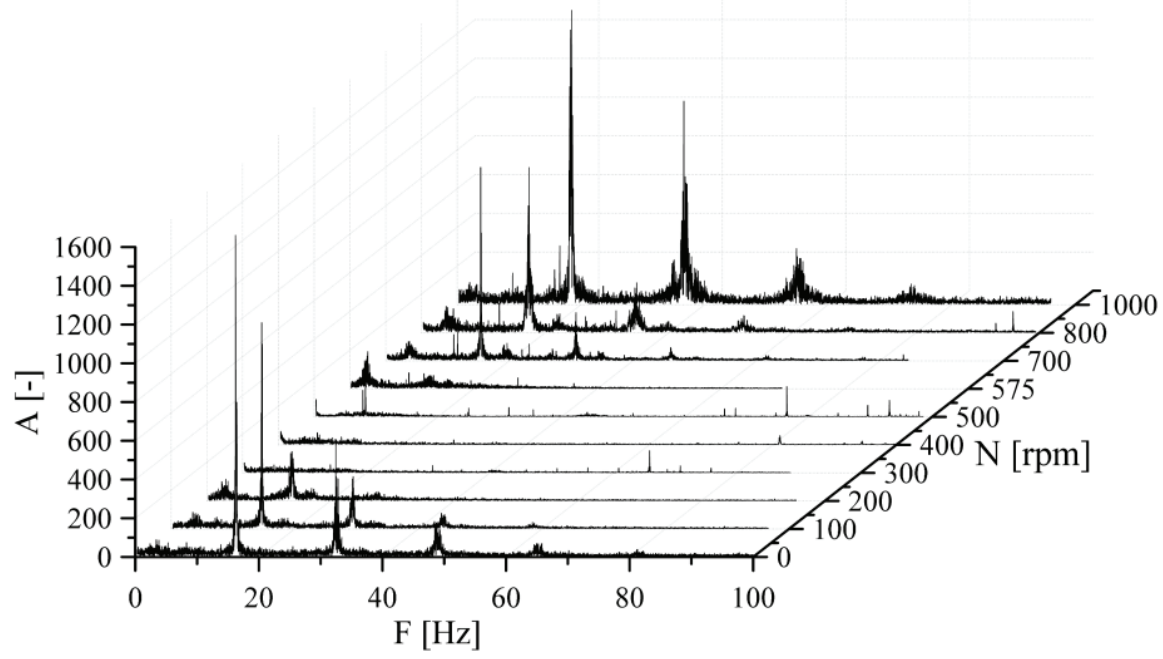

Fig. 3. Pressure spectra diagram at different rotational speed 
It can be seen that the amplitude of fluctuations under the regime with minimal residual swirl falls. Despite the presence of vortex rope at the speed of $500 \mathrm{rpm}$ PVC amplitude is very weak and draft tube pressure pulsation is very small, because the vortex precession radius is much smaller than in the regime of $600 \mathrm{rpm}$ or more. The precession frequency is also reduced, but there is an interesting feature at $\mathrm{N}=500 \mathrm{rpm}$. Precession frequency increases significantly up to $40-50 \mathrm{~Hz}$, these data were obtained through the analysis of high-speed visualisation. After that, the precession frequency falls to $10 \mathrm{~Hz}$ and then it increases monotonically with runner rotational speed.

\section{Conclusion}

Experimental modeling of various flow regimes in a model of hydraulic turbine have been conducted. PVC formation was observed in various forms in a wide range of runner rotational speed. Flow visualization revealed some interesting features of the flow pattern, these are twin vortex breakdown and formation of vortex ring due to reconnection of vortex rope.

Earlier the regime with formation of vortex rings was obtained only on the freelyrotating runner. Here, we defined the position of these phenomena on the regime map [8]. It is shown that the precession frequency of the PVC is dependent on the rotational speed of the runner. The effect of a sharp rise in the precession frequency was observed at a small residual swirl of flow $(\mathrm{N} \approx 500 \mathrm{rpm})$.

This research was supported by the Russian Foundation for Basic Research, grant No 16-08-01191.

\section{References}

1. Skotak, J. Mikulasek, and P. Troubil, Proceedings of the 10th international meeting of the work group on the behavior of hydraulic machinery under steady oscillatory conditions (Trondheim, Norway, 2001)

2. Wen-Tao Su, Xiao-Bin Li, Feng-Chen Li, Xian-Zhu Wei, Wen-Fu Han, and Shu-Hong Liu, Advances in Mechanical Engineering, 2014, 16, (2014)

3. M. Nishi, S. Liu, International Journal of Fluid Machinery and Systems, 6, 1 (2013)

4. S. Skripkin, M. Tsoy, S. Shtork and K. Hanjalić, J. Hydraul. Res., 54, 4 (2016)

5. T. L. Wahl, , Hydro Review, 13, 11994

6. Nicolet, A. Zobeiri, P. Maruzewski, and F. Avellan, Int. J. Fluid Mach. Syst., 4, 1 (2011)

7. Javadi, A. Bosioc, H. Nilsson, S. Muntean, and R. Susan-Resiga, ASME J. Fluids Eng., 138, 82016

8. S. Alekseenko, P. Kuibin, S. Shtork, S. Skripkin and M. Tsoy, JETP Letters, 103, 7 (2016) 